\title{
UnA "GlosA" DE Eugenio D 'Ors sobre Antonio MACHAdo PUBliCADA TRES SEMANAS DESPUÉS DE LA MUERTE DEL ESCRITOR REPUBLICANO
}

\author{
Xesús Alonso Montero \\ Catedrático Emérito de la USC \\ (Presidente de la Real Academia Galega en el período 2013-2017)
}

Title: A "glosa” of Eugenio d'Ors on Antonio Machado published three weeks later of the republican writter's death.

\begin{abstract}
This article, complement and continuation of the one that appeared in number XXIII, 1 (2020), on "Why and by whom was it possible to read the poetry of Antonio Machado in Spain in the early post-war years (Lesson designed, especially, for the young teacher)", analyzes Eugenio dÓrs's approach to the figure of Antonio Machado in 1939 from a newspaper article published by him just a few days after the death of the republican author.
\end{abstract}

Key words: Antonio Machado. Spanish poetry in 1939. Eugenio d'Ors. Literary Historiography.

\section{Para}

Gregorio Ferreiro Fente, amigo e compañeiro a quen tanto estimo, e para Emilia, a súa compañeira, cunha inmensa aperta.

Coas mellores lembranzas,

Xesús

EL TEXTO Y SUS "ARGUMENTOS"

Con el título "La apuesta sobre Antonio Machado" se publicó en El Ideal Gallego (La Coruña) el 16 de marzo de 1939¹. Estaban aún calientes las cenizas del escritor (había fallecido el 22 de febrero) y aún no había finalizado la Guerra de España (Franco entraría oficialmente en Madrid dos semanas después: el 1 de abril de ese año). D’Ors es, sin duda, la pluma

\footnotetext{
${ }^{1}$ Sospecho que se publicó, en esa fecha o fecha muy próxima, en otros periódicos “del Movimiento" en otras ciudades de España.
} 
más valiosa de la intelectualidad franquista, de lo que él era muy consciente. Urgía, por tanto, cuanto antes, sentar cátedra sobre un escritor español que había militado, en el trienio bélico, en la causa de la Antiespaña. Era tan grande don Antonio Machado que las mentes perspicaces del bando franquista tenían que demostrar que el autor de Campos de Castilla, en lo esencial, no fue un defensor y admirador del Frente Popular, de la España "roja”. En este artículo D'Ors arriesga una interpretación: fueron los "rojos", con su brutal presión, quienes "arrancaron" a Antonio Machado "la palabra impía”. Don Antonio, pues, va a ser, en el período bélico, una especie de secuestrado, topos que se inicia en estas fechas y que llega a su máxima formulación en el famoso prólogo de Dionisio Ridruejo. Un escritor de la excelencia y relevancia de don Antonio Machado -opinaban los espíritus menos beocios del gremio franquista- es, en el fondo, más nuestro que de ellos. No aceptaban la admonición cervantina "ex illis est"2.

Ofrezcamos ya, en su integridad, el artículo de Eugenio d'Ors cuyo título va precedido del término "Glosas", sección que el autor mantuvo en distintos periódicos, durante años y años, recogida en volúmenes que tituló, primero, Glosario, y luego, Nuevo glosario. Lo reproducimos sin omitir ninguno de los paratextos de El Ideal Gallego coruñés.

\section{GLOSAS}

La apuesta sobre Antonio Machado

Por Eugenio d'Ors

de la Real Academia Española

Amargura de la Recuperación. Nos devuelven algunos Goyas estropeados. Y un poeta muerto.

Las nuevas canciones de Antonio Machado, las que hubiera escrito un Antonio Machado por fin en libertad, todos las esperábamos con emoción. Y

${ }^{2}$ Cervantes, en su entremés El retablo de las maravillas, recoge el anatema que, en la España del Siglo de Oro, se dirigía a quienes no eran cristianos viejos, sobre todo a los que conversos o no, procedían de la execrable raza judía. Cervantes nos lo transmite en latín (“ex illis est”) y en romance (“dellos es”). 
sus meditaciones giróvagas y profundas, las que él colgaba graciosamente al fantasma de Juan de Mairena.

Dios no podía ofrecernos mejor venganza. A no ser la de verle, otra vez con su hermano, en comunión con su hermano, pasear las calles de alguna vieja ciudad nuestra o sus escenarios nocturnos, tramando, en nueva fabulación los destinos de alguna Lola más allá de los puertos.

Y ahí está, más allá de los que la Lola dejara y de aquellos a que la Lola pudo llegar. Ahí está el poeta, enmudecido para siempre. Tras de la palabra impía que por la fuerza le arrancaran y que ya no está en su mano corregir.

No importa. Lo haremos nosotros por él... Aunque la preocupación de un margen irreductible de azar contrario obligue a revestir nuestra afirmación, como la de la fe en Pascal, de una forma de apuesta.

Apostamos a que Antonio Machado nunca, en la intimidad de su corazón, renegó de Dios ni de España.

Apostamos a que hombre tan fiel al sentido entrañable de la tierra castellana y a los vuelos angélicos del aire andaluz, no pudo sumarse auténticamente con los que violaban esa tierra y escarnecían los impulsos de este aire.

Apostamos a que el cultivador delicado de las soledades no participó de la sanguinaria embriaguez de las masas ni el explorador de las galerías del espíritu, en la agitación por el materialismo histórico.

Apostamos a que el heredero de Góngora nunca traicionó el deber de su nativa aristocracia $-\mathrm{y}$ el de una popularidad tradicional, que también es aristocracia-. Ni el que, de niño, fuera discípulo de don Francisco Giner, la causa de la libertad. Sabedor de cómo era por lo hondo, de que, en la contienda española, liberación quería decir libertad también.

Apostamos a que no votó por la violencia quien había escrito: "No nacen ideas de los puños".

Apostamos a que no militó con Calibán este sacerdote de Ariel.

Apostamos a que un día, liquidadas todas las cuentas, se verá, claro como la luz - claro como nuestra luz-, que la causa roja en España nunca ha tenido verdaderamente a su lado más que unos rebaños de bestias pastoreados por un cuarterón de pedantes.

(Prohibida la reproducción).

Para mí, la clave del artículo de d'Ors, de su alegato, está en estas pocas líneas, ya adelantadas, en parte, en mi introito:

...Ahí está el poeta, enmudecido para siempre. Tras de la palabra impía que por la fuerza le arrancaran y que ya no está en su mano corregir. 
Hay que leer estas líneas relacionándolas con la primera de las siete "apuestas sobre Antonio Machado":

Apostamos a que Antonio Machado nunca, en la intimidad de su corazón, renegó de Dios ni de España.

Que no renegó de España lo prueban unas palabras suyas proferidas en Madrid a comienzos de noviembre de 1936, cuando el V Regimiento evacuó, rumbo a Valencia, a los "sabios" cuyas vidas corrían peligro en la capital de España:

Yo no me hubiera marchado; estoy viejo y enfermo. Pero quería luchar al lado vuestro. Quería terminar una vida que he llevado dignamente, muriendo con dignidad. Y esto sólo podría conseguirlo cayendo a vuestro lado, luchando por la causa justa como vosotros lo hacéis (IV, 2166).

Fueron más que palabras. Sabido es que, a los pocos días de la sublevación militar contra el gobierno de la República (el 31 de julio de 1936), varios eximios intelectuales, entre ellos don Antonio, firmaron este escrito:

Los firmantes declaramos que, ante la contienda que se está ventilando en España, estamos al lado de la República y del pueblo, que con heroísmo ejemplar, lucha por sus libertades.

Ramón Menéndez Pidal, Antonio Machado, Gregorio Marañón, Ramón Pérez de Ayala, Juan Ramón Jiménez, Gustavo Pittaluga, Juan de la Encina, Gonzalo Lafora, Antonio Marichalar, Pío del Río Huerga, José Ortega y Gasset, Ignacio Bolivar... ${ }^{3}$

Algunos de los firmantes no tardaron en solicitar de las autoridades republicanas permiso para viajar al extranjero, entre ellos Menéndez Pidal, Gregorio Marañón, Pérez de Ayala, Juan Ramón y Ortega y Gasset, cinco nombres muy ilustres de la intelectualidad española. Incluso a uno, Marañón, le llegó a publicar un opúsculo envenenado, contra la España leal, el

${ }^{3}$ Declaración publicada en El Sol de Madrid (31-7-1936) y otros periódicos republicanos. La reproduce Ian Gibson en La vida de Antonio Machado. Ligero de equipaje, Barcelona, Punto de Lectura, 2007, p. 592. 
Servicio Exterior de la Falange en la Argentina. Los otros fueron más o menos discretos en sus palabras y actitudes públicas, pero quien quedó en la trinchera, con su voz y con su pluma, fue don Antonio, pese a que, como afirma Oreste Macrì, "Le invitaron a enseñar literatura española en Inglaterra pero quiso permanecer en su puesto" ${ }^{4}$.

Por otra parte, sobre la religiosidad de don Antonio han escrito muchos autores muy distintos, desde los exégetas del verso 26 del "Retrato" ("quien habla solo espera hablar a Dios un día") hasta los comentaristas de esta consideración, ya de 1928:

Estimo oportuno combatir a la Iglesia católica y proclamar el derecho del pueblo a la conciencia, y estoy convencido de que España morirá por asfixia espiritual si no rompe ese lazo de hierro (III, 1525).

Pero sobre España, sobre la idea de España de Antonio Machado y el propio Eugenio d'Ors volveremos.

Fue la causa republicana, para d'Ors, una causa de malvados, si bien, aun en esa barahúnda, Antonio Machado, allá en su fuero interno, nunca “militó con Calibán este sacerdote de Ariel”. Cuando quería, don Eugenio era un panfletario culto. Lo es en esta ocasión en que cita a Calibán, un ser fantástico de una obra de Shakespeare, La tempestad, que representa el espíritu del mal, monstruoso y colérico, opuesto siempre a Ariel.

Eugenio d'Ors figura entre los primeros en el afán de recuperar, para la España "verdadera”, a Antonio Machado. Lo argumentaban como podían. Debemos añadir que en el texto de d'Ors hay un breve párrafo, el referido a “don Francisco Giner”, insólito en la época. La norma era, ante el creador de la Institución Libre de Enseñanza, la descalificación o el insulto. D'Ors, con su auctoritas y su cultura, tenía bula. La cita lo honra.

\footnotetext{
${ }^{4}$ V. la Introduc. en el tomo I de Poesía y prosa, ed. de Oreste Macri, Clásicos Castellanos, 1988.
} 
¿QuiÉn erA, Entonces, Eugenio D'Ors, y Desde dónde habla$\mathrm{BA}$ ?

Fuera de Cataluña poco se sabe, entre los lletraferits, de Eugenio d'Ors i Rovira (Barcelona, 1881- Vilanova i la Geltrú, 1954), que firmó no pocas páginas suyas con el seudónimo, muy del personaje, "Xenius". Histrión y tornadizo, sus libros y trabajos sobre Estética y Arte son importantes, y lo fueron especialmente en su época. En ese campo y en otros géneros, es autor de títulos muy significativos en catalán hasta 1920, año en que abdica - si se me permite la expresión- como escritor en lengua catalana. Desde entonces, con sus “Glosas” y otras páginas, su voz suena fuerte en las letras castellanas. En 1927 ya es elegido miembro numerario de la Real Academia Española, institución que gobernará, en parte, en los primeros años del franquismo y a la que llevará algunos de sus efluvios retóricos.

Ahora bien, el d'Ors de los primeros años del franquismo es un personaje, una creación suya, verdaderamente lamentable. De los testimonios de la época ofrezco uno de quien, en aquellas fechas era afín en ideas. Se trata de un texto de Dionisio Ridruejo escrito en 1974 tratando de captar la personalidad del "Xenius" de 1937:

Cuándo le conocí frente a frente -verbo a verbo-, dirigía una tertulia en la Pamplona militarizada. Disponía de un par de acólitos -el fino A. M. Pascual, el retórico Izurdiaga - y de media docena de oyentes casi amigos: Laín, Rosales, Vivanco, Torrente Ballester, Follaca, García Serrano. Un día pasó por allí el imaginativo y rústico Martín Almagro, el paleontólogo que nos contaba historias de los Celtas y del "matriarcado". Cuando se marchó pregunto d'Ors: “QQuién es ese pastor iluminado?".

Había, en esta etapa de d'Ors - aún distante para mí- un cierto exceso de caracterización. Invitado con insistencia a inscribirse en la Falange, d'Ors exigió la ceremonia de armarse caballero y lo hizo en una iglesia quedándose a velar con la espada sin funda y un pastel con velas en el altar. Llevaba para lectura un devocionario francés. Oficiaba el P. Izurdiaga. El granadino Rosales contó la historia de un modo tan divertido que d'Ors nunca quiso saber más de él porque le suponía, además - y casi inexactamente- autor de un soneto satírico. En el periódico Arriba España donde el Glosario se había hecho ya "novísimo", hizo o aceptó que le pusieran a la altura de la cabeza en la pared donde se apoyaba su silla de trabajo- una invocación a los ángeles 
custodios. Se hizo además un uniforme pintoresco: camisa, "breaches" con lequis y zapato bajo, sombrero redondo. Cuando alguien una vez le dijo: “Maestro: Vd. cada vez más joven”, él respondió: “No, cada vez más eterno”. Seguramente fue ésta la época menos grata de recordar de la vida de d'Ors. Él no necesitaba aquellas zarandajas para ser quien era, la primera cabeza del medio ruedo ibérico que le acogía, y para los demás que le respetábamos y a los que todo aquello nos sobraba mantenía perplejos. Pero duró poco. D'Ors salió de Pamplona para ser Director General de Bellas Artes y Secretario Perpetuo del Instituto de España ${ }^{5}$.

Los profesores jóvenes de hoy, para quienes, en especial, exhumamos éste y otros textos, no darán crédito. La ceremonia en que fue armado caballero falangista exigida por el propio Xenius, resulta inconcebible.

En diciembre de 1937 Eugenio d'Ors fue nombrado Secretario Perpetuo del Instituto de España, institución que acogía en su seno las seis Reales Academias, academias que se reunieron en el Paraninfo de la Universidad de Salamanca el 5 de enero de 1938 para formalizar el ingreso -o reingreso- de sus miembros numerarios. El juramento, ideado y redactado por d'Ors, rezaba:

- (Habla el Presidente). Señor Académico, zjuráis ante Dios y ante Nuestro Ángel Custodio servir perpetua y lealmente a España, bajo imperio y norma de su tradición viva; en su catolicidad, que encarna el Pontífice de Roma; en su continuidad, hoy representada por el Caudillo Salvador de nuestro pueblo?

- (Académico) Sí, juro.

- (Presidente) Si así lo hicieseis, Dios os lo premie, y si no, os lo demande.

El juramento se hacía ante una mesa que sostenía dos volúmenes: un ejemplar de los Evangelios (con el texto de la Vulgata) y otro del Quijote, ornado en la cubierta con el Yugo y las Flechas. Durante la lectura el académico posaba su mano derecha en el volumen bíblico. El texto del juramento, sin duda de d'Ors, transpira retórica d'orsiana en su formulación:

\footnotetext{
5 "Eugenio d'Ors. Xenius en estatua", en Sombras y bultos, Barcelona, Destino, 1977, p. 83.
} 
“nuestro Ángel Custodio”, “bajo Imperio y norma de su Tradición”... Por cierto, la Tradición nos remite a un aforismo suyo, muy grato para él: "Lo que no es tradición es plagio". Sobre el Caudillo, el mismo d'Ors, después de velar armas para hacerse caballero falangista, sentenció:

No quiero, ni puedo, ni debo tener hoy otro parecer que el de mi Caudillo, a quien... he jurado lealtad... tras velar en la iglesia de San Andrés de Pamplona las armas de la Caballería andante ${ }^{6}$.

En 1938, Eugenio d'Ors fue nombrado Doctor Honoris Causa por la Universidad de Coimbra en cuya biblioteca descubrí y transcribí, hace más de veinte años, algunas de las cartas que el Eugenio español le envió al Eugenio portugués, a Eugenio de Castro (1869-1944), escritor y diplomáti$\mathrm{co}^{7}$. Son muy representativas de la fatuidad de Xenius, que casi no conocía límites. En la del 10 de julio de 1938 lo despide con esta retórica tan suya y $\tan$ fascistoide:

Mi Ángel Custodio se inclina ante el suyo y le dirige el saludo romano.

Al lado del membrete de Instituto de España, del que d'Ors es secretario perpetuo, escribe a mano:

Gesta Dei

per Franco

Poco antes, le había enviado este telegrama, un texto inscribible, perfectamente, en la estrategia de su personal glorificación:

${ }^{6}$ Texto recogido por Enri Jardi en su libro Eugenio d'Ors: Obra $i$ vida, Barcelona, Quaderns crema, 1990, p. 261.

${ }^{7}$ Ignoro si las cartas que exhumo fueron publicadas alguna vez. En cualquier caso, aquí se aducen como testimonios del personaje Eugenio d'Ors que este tanto cuidaba y perfeccionaba. 
Instituto de España

Ruego comunique aceptaría homenaje poetas españoles llegados a Coimbra el ocho mayo

Saludo romano

Eugenio d'Ors. Secretario perpetuo

Era el día de su doctorado coimbrigense. Cuando, el 14 de mayo, se despide del escritor portugués, al lado de una fotografía de ambos, estampa estos ocho versos:
Poeta luso, filósofo de España, los dos aquí salimos disfrazados.
Yo, con mis botas negras, condotiero, tú, con pechera blanca, diplomático.
Horas vendrán en que, modestamente, podamos regresar a nuestras clases:
Yo, por pensar cordura, la de Sócrates, tú, por cantar poesía, la de Dante.

Rebus sic stantibus, ha llegado el momento de volver a una de las secuencias más significativas del artículo que Eugenio d'Ors publicó, sobre don Antonio Machado, pocos días después del fallecimiento del autor de Juan de Mairena, heterónimo que Xenius no elude en su nota necrológica. Es la secuencia ya mencionada: "Apostamos a que Antonio Machado nunca, en la intimidad de su corazón, renegó de Dios ni de España”. La España que Xenius, con su retórico ingenio, representa e inventa, ciertamente no es la España de don Antonio Machado. En cuanto a Dios y a la religión, ¿qué diría don Antonio de la ceremonia seudoquijotesca, oficiada por el cura falangista Fermín Yzurdiaga, en la iglesia de Pamplona? ¿Qué opinaría sobre esa perla latino-medieval "Gesta Dei per Franco"?

Lo que está claro es que Eugenio d'Ors percibe la necesidad de recuperar para la "verdadera" España el nombre y la obra literaria de Antonio Machado y lo hace, desde el totum revolutum de su personaje, como mejor 
puede en un artículo, donde, aquí y allí, hay algunas palabras nobles, sobre todo las referidas a don Francisco Giner de los Ríos ${ }^{8}$.

No debemos omitir que Eugenio d'Ors, aún en esta época tan histriónica, tan fantoche, estaba agradecido a unos versos de don Antonio. Se trata de un soneto de 1921 (II, 661) que constituye un sincero homenaje a la inteligencia de "Xenius" y a su literatura, hasta entonces formulada en catalán.

Recibido: septiembre de 2020

Aceptado: noviembre de 2020

${ }^{8}$ Cuando al final de un texto consigno un número romano y otro arábigo, aquel indica el tomo y este la página de alguno de los cuatro volúmenes de la Poesía y Prosa de A. Machado en la ed. de Oreste Macrì (Clásicos Castellanos, 1988). 